\title{
The collision of masses and the way prices react to expectations
}

\author{
Luis Chavez-Guzman* \\ UDEM, Departamento de Administracion, Division de Negocios, Universidad de Monterrey Morones Prieto \\ 4500 Pte, Garza Garcia, NL 66238, Mexico
}

Received 16 December 2003

Available online 23 July 2004

\begin{abstract}
When a body is impacted by other bodies its position is determined by the force of the impacts, likewise the price of a share is determined by expectations. This study intents to establish taxonomy of expectations based on the different types of impacts a body can receive, these can be: a blow without penetration, a blow that penetrates and stays in the body, a blow that goes through the body without affecting the body mass, and lastly, a blow that reduces but does not penetrate the body mass.
\end{abstract}

(c) 2004 Elsevier B.V. All rights reserved.

PACS: 89.65.Gh; 45.50.Tn; 45.20.-y; 06.30.Dr

Keywords: Mass; Elementary impacts; Share prices; ISO 9000; Mass

\section{Introduction}

In finance literature, it is said that expectations are expressed in the price of the share in the market. In the analogy, the mass in the physical world that is impacted permits to see clearly the types of impacts that may occur and if we take this to the financial field, we can analyze the financial part more deeply. This gives us the

\footnotetext{
*Tel.: 52-81241481; fax: 52-81241235.

E-mail address: lchavez@udem.edu.mx (L. Chavez-Guzman). 
opportunity to propose a new definition of the bases of the financial theory with a more sophisticated way of solving processes.

The determination of the price of shares in the market is a basic topic in the knowledge of the financial theory; for example, a classification of what we do know about finance mentioned by Brealey and Myers [1] where they mention the seven most important ideas in finance: net present value, the capital asset pricing model, efficient capital markets, value additivity and the law of conservation of value, capital structure theory, option theory and agency theory, where the formation of the prices of shares is directly related to the second and third ideas.

This study intends to establish taxonomy of expectations based on the different types of impacts a body can receive. These can be: a blow without penetration, a blow that penetrates and stays in the body, a blow that goes through the body without affecting the body mass, and lastly, a blow that reduces but does not penetrate the body mass.

\section{Connection between physics and financial concepts}

Taking into consideration a particle with a mass $\mathbf{M}$ in a space without friction, under the influence of a field of gravitation, receiving the impacts of particles containing mass and moving at the same two-dimension space.

In other respects, taking into account the price of a share that integrates, in its price, the information of the market, we may establish the following similitude (Table 1).

\section{The portfolio of shares}

A portfolio of shares would be similar to a set of particles, each one of these being affected by its respective fields of gravitation. The weights of the portfolio relate to the number of identical bodies and not to the mass of the body.

The return expectation of the portfolio would correspond to the relative move of the cloud of bodies to its initial position in a lapse.

The deviation of the returns of the portfolio is similar to the amplitude of the moves relative to the initial position of the cloud of bodies in a lapse.

$$
\begin{aligned}
& R=\frac{V}{d_{0}}, \\
& R_{p}=\left(w_{1} R_{1}+w_{2} R_{2}+\cdots+w_{n} R_{n}\right), \\
& \frac{V}{d_{0}}=\frac{w_{1} V_{1}}{d_{1,0}}+\frac{w_{2} V_{2}}{d_{2,0}}+\cdots+\frac{w_{n} V_{n}}{d_{n, 0}},
\end{aligned}
$$

where $R_{i}$ is the return of body $i, V_{i}$ is the velocity of body $i, w_{i}$ is the part invested in the share $i, d_{i, 0}$ is the initial position of body $i,(1)$ is the return expressed as the 
Table 1

\begin{tabular}{|c|c|}
\hline Collision of masses & Prices formation \\
\hline $\begin{array}{l}\text { The position of body } P \text { in the field of } \\
\text { gravitation. Distance. }\end{array}$ & The price of the share in the market. \\
\hline Particles $p$ that may impact $P$. & $\begin{array}{l}\text { Information that has a possible impact on the } \\
\text { price of the share. }\end{array}$ \\
\hline $\begin{array}{l}R \text { change in the position of } P \text {, increase in the } \\
\text { distance related to the initial distance in a } \\
\text { lapse of time. }\end{array}$ & Return of a share. \\
\hline The mass $M$ of a body $P$ inertia. & $\begin{array}{l}\text { The influence of the past price or tendency of } \\
\text { the price of the share. }\end{array}$ \\
\hline $\begin{array}{l}\text { The part of the mass of particle } p \text { that } \\
\text { remains in } P \text { after the impact when it is a } \\
\text { blow that penetrates and stays in the body. }\end{array}$ & $\begin{array}{l}\text { Information that makes the price of the share } \\
\text { more sensible to the past price or tendency } \\
\text { diminishing relatively its volatility to the } \\
\text { events of the market. }\end{array}$ \\
\hline $\begin{array}{l}\text { The part of the mass of } P \text { that is reduced } \\
\text { when it is impacted by the particle } p \text {; it is a } \\
\text { blow that reduces but does not penetrate the } \\
\text { body mass. }\end{array}$ & $\begin{array}{l}\text { Information that makes the price of the share } \\
\text { less sensible to the past price or tendency } \\
\text { increasing relatively its volatility to the events } \\
\text { of the market. }\end{array}$ \\
\hline Fields of gravitation $G_{i}$ & $\begin{array}{l}\text { Aspects that are taken into consideration by } \\
\text { investors when they take part in the sale of } \\
\text { the shares. }\end{array}$ \\
\hline $\begin{array}{l}\text { Field of gravitation that impacts the share. } \\
\text { Sum } G=G_{1}+\cdots+G_{n}\end{array}$ & $\begin{array}{l}\text { The way in which the market combines and } \\
\text { balances the information in the case of a } \\
\text { specific share in order to take a decision } \\
\text { about the sale. }\end{array}$ \\
\hline$m v$ Quantity of motion. & The stability of a tendency. \\
\hline$V$ Velocity of the particle. & $\begin{array}{l}\text { Increase in the price in a specified period of } \\
\text { time. }\end{array}$ \\
\hline$A$ Acceleration of the particle. & Increase in price by day. \\
\hline$F$ Force acting on the particle. & $\begin{array}{l}\text { The importance of the information for the } \\
\text { change of tendency. }\end{array}$ \\
\hline F.t Work. & $\begin{array}{l}\text { The importance and permanence of the } \\
\text { information that increase the price. }\end{array}$ \\
\hline Mgh Potential energy. & $\begin{array}{l}\text { The price of the share being zero, it is difficult } \\
\text { to obtain the conditions that would allow the } \\
\text { share to have a price. }\end{array}$ \\
\hline
\end{tabular}

velocity divided by the initial position and (2) is the return of the portfolio and (3) in the particles.

\section{Factors that determine the price of the share}

To have a more precise idea about the factors that are taken into consideration by investors who take part in the sale of shares, which in physics would correspond to fields of gravitation $G_{i}$, we made a survey of 105 students, at the end of their studies in the departments of business administration, marketing, international trade and public accountancy of the University of Monterrey. They were asked to play the role 
of investors and to mention the three most important factors in the formation of the price of the share in the market $G_{1} \ldots . G_{n}$. After an analysis of the information, we found that the factors are: background of quality, ability of the personnel, adequate organization, interdepartmental organization, leader on the market, positioned brand marks, labor atmosphere, humanistic style, fidelity, stability of sales, important sales, large markets, perspective of growth, capacity of innovation, efficiency in production, technology in production, relations with customers, visionary capacity, promising industry, distribution, diversification, low debt, international diversification, handling of cash, systems of planning, competitiveness, realistic goals, capacity of adaptation, size of the firm, handling of trade unions and ecological conscience.

\section{The different types of impacts}

Recent evidence suggests that the market under-reacts to the information revealed by earnings reports and announcements of some financial decisions.

\subsection{A blow without penetration}

In this case, the effect of the expectation on the price of the share does not modify the way in which the price of the share reacts to influence, as before, and measures of sensibility like beta do not modify it as consequence of the impact of the expectation.

Those impacts are those that have been found by Grinblatt et al. [2], who conclude that stock prices increase, on average when firms increase dividends and decrease, on average, when they decrease dividends.

Aarts and Vos [3] found that the announcement of ISO certification by New Zealand Firms was a blow without penetration and without influence on the price of share.

\subsection{A blow that penetrates and stays in the body}

It is the expectation that, apart from being integrated in the price, modifies the way in which the price of the share reacts to the events related to $G_{1} \ldots . G_{n}$; among other things, beta changes, that is to say, modifies the way of reacting to the impact of the following expectations. The body acquires an extra mass and the events affect it less; this is the case of mergers and acquisitions, diversification etc.; beta diminishes.

Martin and Vos [3] found that the price of the share rapidly integrated the information generated in the process of obtaining the ISO certification and that was a blow that penetrated and stayed in the body; this is what happens when a market is efficient in its semi-strong shape. 


\subsection{A blow that goes through the body without affecting the body mass}

The body reacts to the blow with a move and the importance of the move depends on the mass of the body and on the velocity and mass of the particle that impacts it.

The study of Keown and Pinkerton [4] mentions that it is on the same day and Patell and Wolfson [5] show that "when a firm publishes its latest earnings or announces a dividend change, the major part of the adjustment in price occurs within 5-10 min of the announcement", they only take into consideration the final result, that is the movement of the body, and this gives us an idea of the velocity of the process generally. Keown and Pinkerton [4] also mention that the process, in some cases, permits to a group of minority investors to know more than the market and anticipate. It is this information, when progressively appearing in the market, that may be considered as a blow that goes through moving and taking into account the fact that the information is perishable or not, it will affect or not the mass of the body.

\subsection{A blow that reduces but does not penetrate the body mass}

It is the expectation that, apart from being integrated in the price, modifies the way in which the price of the share reacts to the events related to $G_{1} \ldots . G_{n}$; among other things, beta changes, that is to say, modifies the way of reacting to the impact of the following expectations.

The body diminishes its mass and is more volatile; the events affect it more when the firm decides to abandon markets, reduce its activity to a few products among other things and beta increases.

\section{Conclusion}

The classification of the proposed impacts in this work is the beginning of future investigations where it will be possible to include other concepts of physics that will allow a deeper analysis of finances. The experience of establishing the physical analogy of a financial process allows us to value the grand flexibility that the concepts of physics present. The information that affects the prices of the shares barely corresponds to a single type of impact; it contains two or more of these types of impacts that we might call "elementary impacts". This work is an intent to define the elementary impacts that will be used as a basis for future analogies.

\section{References}

[1] R.A. Brealey, S.C. Myers, Principles of Corporate Finance, sixth ed., Irwin/McGraw-Hill, USA, 2000.

[2] M.S. Grinblatt, R.W. Masulis, S. Titman, The valuation effects of stock splits and stock dividends, J. Financial Econ. 13 (1984) 461-490.

[3] F.M. Aarts, E. Vos, The impact of ISO registration on New Zealand Firms' performance: a financial perspective, TQM Mag. 13 (3) (2001) 180-191. 
[4] A.J. Keown, J.M. Pinkerton, Merger announcements and insider trading activity: an empirical investigation, J. Finance 36 (4) (1981) 855-869.

[5] J.M. Patell, M.A. Wolfson, The intraday speed of adjustments of stock prices to earnings dividend announcements, J. Financial Econ. 13 (1984) 223-252. 